\title{
A Situational Model of Sexual Assault Prevention through Bystander Intervention
}

\author{
Shawn Meghan Burn
}

\begin{abstract}
Bystander intervention is a potentially potent tool in the primary prevention of sexual assault but more information is needed to guide prevention programs (Banyard 2008). Undergraduates (378 women and 210 men, primarily White) at a central coast California university completed an anonymous questionnaire measuring five barriers identified by the situational model of bystander intervention (Latane and Darley 1970) and bystander intervention behavior. As expected, the barriers were negatively correlated with intervention, were greater for men than for women, and intervention likelihood was affected by perceptions of victim worthiness, especially for men. Hypotheses predicting a positive relationship between having a relationship with the potential victim or perpetrator and intervention were supported. Implications for sexual assault bystander intervention programming are provided.
\end{abstract}

\section{Introduction}

Barriers to Bystander Intervention in Situations At-risk for Sexual Assault

Approximately $25 \%$ of American college and university women are survivors of rape or attempted rape (Fisher et al. 2000; Tjaden and Thoennes 2000). At least two thirds of rapes are perpetrated by someone known to the victim, often in a party or date situation, and often involving drug or alcohol intoxication (Brecklin and Ullman 2005; Carr and Van Deusen 2004; Fisher et al. 2000; Tjaden and Thoennes 2000; Ullman 2003). Because bystanders are often present during the pre-assault phase where markers of sexual assault risk are present, sexual assault prevention programming focusing on bystander intervention may be useful (Banyard et al. 2004; Berkowitz 2002; Foubert 2000; Katz 1995; O’Brien 2001; Schewe 2002). However, more social-psychological study of bystander intervention as it applies to specific interpersonal violence contexts is needed (Banyard 2008). This correlational study conducted with American undergraduate students provides a preliminary test of a situational model of sexual assault bystander intervention based on Latane and Darley's (1970) situational model of bystander intervention. According to the model, bystanders must first notice the event, then identify it as one where intervention is needed, then take responsibility for intervention, then decide how to help, and finally, act to intervene. Situational barriers at any of these steps halt the bystander intervention process (Latane and Darley 1968, 1970; Latane and Nida 1981). Sexual assault bystander intervention is examined in regards to these steps and barriers. Other variables from the social-psychological research literature on gender, helping behavior, and perceptions of sexual assault survivors are applied to further our understanding of sexual assault bystander intervention and potentially inform prevention programming.

Sexual Assault Prevention and Risk Reduction Programs

Sexual assault prevention and risk reduction programs are now found at most United States colleges and universities. A review of the sexual assault prevention research literature from 1970 to 2002 identified two broad categories of 
programming, self-defense trainings and educational programs (Sochting et al. 2004). Mixed-gender attitude (educational) programs are more prevalent than self-defense programs and include information on sexual assault prevalence, debunking rape myths and rape supportive attitudes, discussions of gender-stereotypical behavior, and practical suggestions for safe dating behaviors (Bachar and Koss 2001; Sochting et al. 2004). Although common at universities, attitude changes usually revert to previous levels within months, men's rape-supportive attitudes sometimes increase, and there are only weak effects on sexual assault incidence (Breitenbecher 2000; Rozee and Koss 2001; Sochting et al. 2004).

Anderson and Whiston (2005) identified four primary types of content in sexual assault prevention education programs: informative (provide factual information and statistics, review myths and facts, consequences of rape, and rape scenarios); empathy focused (help participants develop empathy for rape victims); socialization focused (examine gender-role stereotyping, societal messages that influence rape); and risk reducing (teach specific strategies to reduce one's risk of rape). Their meta-analysis of 69 empirical studies found statistically significant effect sizes for rape knowledge, rape attitudes, behavioral intent, and incidence of sexual assault. However, only the category of rape knowledge reached the criteria for a moderate effect size; the other three did not meet the criteria for even a small effect size. They concluded that sexual assault education programs are somewhat effective in changing attitudes toward rape and rape knowledge, but "if effectiveness is defined solely as a decrease in sexual assault, then there is little support available from the current pool of studies" (p. 381).

\section{Bystander Intervention and Sexual Assault Prevention}

Recent recommendations for more effective sexual assault prevention programs include a focus on the role of the bystander (Banyard et al. 2004; Berkowitz 2002; Schewe 2002). In contrast to traditional prevention education programs that address audience members as potential perpetrators or potential victims, bystander education programs address audience members as potential bystanders that can intervene to prevent sexual assault (Banyard 2008; Lonsway et al., in preparation). The approach may include training people to interrupt a sexual assault or situations that may lead to sexual assault, teaching them to speak out against social norms supportive of sexual violence, and preparing them to provide support to survivors (Banyard et al. 2007). A bystander approach to sexual assault prevention has potential benefits. Banyard et al. (2004) suggest that bystanders can help create new community norms for intervention to prevent sexual assault, increase others' sense of responsibility for intervening and their feelings of competence, and provide role models of helping behavior. A bystander focus creates less defensiveness because people are approached as potential allies rather than as potential victims or potential perpetrators (Banyard et al. 2004; Berkowitz 2002). An emphasis on bystanders as prevention agents also reduces the burden of sole responsibility for rape avoidance often placed on the potential victim (Ullman 2007). Moreover, most sexual assaults are perpetrated by a small percentage of serial perpetrators (Lisak and Miller 2002) whose motivations for assault are complex and hard to change. If however, people can learn to recognize situations in which others are at risk for sexual assault, take responsibility for intervening, and know how to intervene, then sexual assault could potentially be reduced.

Although bystander intervention in the context of sexual assault prevention may be defined broadly, the focus here is on bystanders taking preventative action when there are markers of high-risk for the sexual assault of college women by men. For example, among college students, bystanders (friends and/or other partygoers) are frequently present in the pre-assault phase and yet do not intervene to reduce others' sexual assault risk. High-risk markers include: women going to a private location with male acquaintances, women left alone by their friends at a party or bar, intoxication (of potential victim or perpetrator or both), walking or running alone in secluded locations or at night, and the presence of a man exhibiting "pre-rape behaviors" (see Rozee and Koss 2001 for a list of possible pre-rape behaviors). The following are examples of preventative bystander intervention actions in women: a woman insists that her friend not run alone in secluded locations or at night; a group of women refuse to leave their intoxicated friend alone at a party or bar; and, women at a party prevent a woman from going to a private location with a male acquaintance. For men, examples of preventative bystander intervention behaviors include: a man reminds his male friend that consent is the difference between sex and sexual assault and that the woman is too intoxicated or underage to provide consent; a group of men prevent a man from taking an intoxicated woman to a private location; a group of men tell a man trying to take sexual advantage of another person he must leave a party. Prevention bystander intervention also includes calling or locating an authority.

The best-known model of bystander intervention is the situational model created by Latane and Darley (1970). The five-step model suggests that the decision to intervene is complex: bystanders must first notice the event, interpret it as an emergency, take responsibility for acting, decide how to act, and choose to act. Furthermore, potential barriers at any of the steps may thwart bystander 
intervention. The application of the model to sexual assault bystander intervention is outlined below and summarized in Table 1.

According to the situational model, the first step towards helping is for the bystander to notice the event. Bystander distraction resulting from self-focus or sensory distractions may lead to a failure to notice barrier. For example, bystanders may fail to notice a potential sexual assault at a social gathering or party because they are distracted by the noise or their own social activities. Their attentional and perceptual processes may also be compromised by intoxication.

The second step is to identify the situation as intervention appropriate. In other words, bystanders must interpret the situation as high in sexual assault risk. Ignorance or ambiguity can create a failure to identify the situation as high risk barrier. While violent and dangerous emergencies reduce ambiguity and therefore reduce the bystander effect (Fischer et al. 2005; Harari et al. 2001), sexual assault risk in many situations may be ambiguous. For example, it may be unclear whether the man talking to or touching the intoxicated woman is a danger to her. Ignorance of sexual assault risk markers or what constitutes sexual consent may also prevent interpretation of a situation as high in sexual assault risk. Women may not realize they put their friend at risk when they leave her alone at the party or bar or let her go to a private location with a man. Men may be unaware that their friend is at risk for sexually assaulting because they do not know that intoxicated women cannot provide true sexual consent. Ambiguity regarding the relationship between the potential victim and potential perpetrator may also make a difference as bystanders are less likely to intervene in a situation involving violence against a woman if they believe there is a romantic relationship between them (Shotland and Straw 1976). Another potential problem is that when situations are ambiguous, people rely on others' reactions to help them decide what to do. Pluralistic ignorance occurs when ignorant, inactive bystanders look to other ignorant, inactive bystanders and consequently all fail to identify the situation as intervention appropriate (Latane and Darley, 1968). Banyard's (2008) finding that bystander intervention was positively associated with knowledge about sexual violence suggests that knowledge reduces this barrier because bystanders are better able to identify when others are at-risk.

The third step is to take intervention responsibility. Bystanders may recognize that another is at risk for sexually assaulting or being sexually assaulted, but will not intervene if they do not feel it is their responsibility. The failure to take responsibility barrier is affected by the presence of other bystanders, the relationship of the bystander to the potential victim or perpetrator, and beliefs about the potential victim's "worthiness." As the number of bystanders increases, responsibility becomes "diffused" such that each bystander feels a decreased sense of intervention responsibility (Latane and Darley 1970). This diffusion of responsibility is especially likely when bystanders are not cohesive and social norms do not support intervention (Rutkowski et al. 1983). Bystanders feel more responsible for intervening when they have a relationship with the potential victim or the victim is an ingroup member (Gottlieb and Carver 1980; Howard and Crano 1974; Levine et al. 2002). Levine et al. (2002) suggest that bystanders witnessing aggressive ingroup members may

Table 1 Barriers to bystander intervention in situations at risk for acquaintance rape.

\begin{tabular}{lll}
\hline Step & Barrier & Influences \\
\hline $\begin{array}{l}\text { 1. Notice event } \\
\begin{array}{l}\text { 2. Identify situation as } \\
\text { intervention appropriate }\end{array}\end{array}$ & Failure to notice & $\begin{array}{l}\text { Noise and other sensory distractions } \\
\text { Self focus (focus on own activities) } \\
\text { Ambiguity regarding consent or danger }\end{array}$ \\
3. Take responsibility & Failure to take intervention responsibility & $\begin{array}{l}\text { Pluralistic ignorance } \\
\text { Ignorance of sexual assault risk markers } \\
\text { Diffusion of responsibility (likelihood greater if } \\
\text { there are many other possible interveners) }\end{array}$ \\
& & $\begin{array}{l}\text { Relationship of bystander to potential victim and } \\
\text { potential perpetrator } \\
\text { Attributions of worthiness (affected by perceived } \\
\text { choices of potential victim that increased her risk, } \\
\text { perception of potential victim's provocativeness, } \\
\text { and her intoxication) }\end{array}$ \\
& Action ignorance (don't know what to say or do to \\
& intervene)
\end{tabular}


exhibit ingroup bias and be less likely to intervene unless the aggressive members are seen as damaging the reputation of the group (i.e., the black sheep effect). It should be noted however that there is little research on this issue in regards to sexual assault bystander behavior with the exception of Banyard (2008), who found no relationship between knowing the victim and bystander behavior.

Attributions regarding the worthiness of the victim may also reduce feelings of intervention responsibility (Loewenstein and Small 2007). For example, greater responsibility is placed on sexual assault survivors when they dressed provocatively (Workman and Freeburn 1999; Cassidy and Hurrel 1995; Schult and Schneider 1991; Whatley 2005). Perceptions of victim worthiness are also influenced by substance use by the victim and perpetrator. When the victim and perpetrator consumed alcohol, acquaintance rape is not judged as severely by others (Norris and Cubbins 1992). Peers also tend to hold women more responsible for the act than they do men even when both the female victim and male offender were equally intoxicated (Abbey et al. 1996; Castello et al. 2006; Sampson 2003; Fogle 2000). However, one study found that when sexual assault victims were promiscuous or intoxicated, ingroup victims were perceived more positively than outgroup victims (Harrison et al. 2008). Women who drink in bars are also viewed as legitimate targets of sexual aggression (Abbey et al. 1996).

The fourth step on the path to bystander intervention is to decide how to help and the main barrier at this a failure to intervene due to a skills deficit (Cramer et al. 1988; Shotland and Heinhold 1985). Bystanders may be uncertain about what to say or do when another is at risk for assaulting or being assaulted and this may lead to a failure to intervene due to a skills deficit. One study found that self-perceptions of bystander efficacy in regards to interpersonal violence were positively associated with bystander behavior (Banyard 2008). Finally, the fifth step, act to intervene, can be impeded by bystander fears of embarrassment, awkwardness, and social concerns, leading to a failure to intervene due to audience inhibition barrier (Latane and Darley 1970). Audience inhibition may depend on "local" norms and whether they support intervention (Rutkowski et al. 1983; Schwartz and Gottleib 1980). Evaluation apprehension (anxiety at the thought of possible negative evaluations from others) may also prevent action if bystanders fear making a mistake. This inhibitory factor may be greater for newcomers seeking acceptance, such as new students and or Greek system pledges. Latane and Darley (1970) note that the potential costs of making an inappropriate response increase as the number of bystanders increase. Taken together, findings suggest that audience inhibition may reduce bystander intervention at large parties or in bars unless there are salient social norms consistent with intervention.
Gender and Sexual Assault Bystander Intervention

Although there is no research on gender differences and the situational model of bystander intervention, past research leads to some tentative gender difference hypotheses in regards to the model when applied to sexual assault prevention. For example, in comparison to men, women's greater risk of sexual assault (Tjaden and Thoennes 2000) may make sexual assault risk more salient to them thereby reducing the failure to notice barrier and the failure to identify a situation as high risk barrier. The ambiguity inherent in many high risk situations may also more adversely affect men's intervention. Men are more likely to help in emergency situations or when "heroic, chivalrous" help is appropriate (Eagly and Crowley 1986) and prevention bystander intervention often requires intervening prior to that point. Women's greater skill at reading others' emotions (Hall 1984) and their more relational, interdependent focus (Eagly 1987) may also aid in women's ability to notice and diagnose a situation as one where another woman is at risk.

A number of research findings suggest that the failure to take intervention responsibility barrier may be larger for men than women. For example, research on rape myths suggests that men may be less likely to take intervention responsibility when women are at risk for sexual assault. Rape myths are false attitudes and beliefs about rape and include a willingness to assign blame to sexual assault survivors (Lonsway and Fitzgerald 1994). Consistent with Burt's (1980) suggestion that rape myths may be used to cognitively justify rape and ignore social prohibitions against hurting others, rape myth acceptance is linked to sexual assault perpetration (cf. Aosved and Long 2006). Research finds that men tend to believe more strongly in rape myths than women (Lonsway and Fitzgerald 1994; Shechory and Idisis 2006) and this may translate into gender differences in intervention responsibility.

Perceptions of similarity between oneself and others can allow an individual to take others' perspectives (Cialdini et al. 1997), increasing feelings of empathy, which in turn, increases the likelihood of helping others when they are in need (Batson et al. 2007; Loewenstein and Small 2007). Women are more likely to identify and empathize with victims of sexual assault than men are (Ching and Burke 1999; Deitz et al. 1982; Gerber et al. 2004; Jimenez and Abreu 2003; Lambdin 2005), and men tend to be higher on rape perpetrator empathy (Smith and Frieze 2003). Consequently, women may be more likely to take intervention responsibility. Likewise, research finds that perceptions of victim worthiness influence willingness to provide help and men, more than women, place greater responsibility on sexual assault survivors when they dressed provocatively (Workman and Freeburn 1999; Cassidy and Hurrell 1995; 
Schult and Schneider 1991; Whatley 2005). In general, research suggests that attributions of responsibility to sexual assault survivors may exert a stronger negative influence on men's intervention (Gerber et al. 2004; Grant et al. 1995).

Gender differences in the failure to intervene due to a skills deficit may depend on the type of intervention needed. Here the focus is on simple, specific assertive intervention behaviors rather than behaviors characterized by heroic action (where men may be advantaged) or helping in the context of a long-term relationship such as helping a sexual assault survivor (where women may be advantaged). In the case of intervening to prevent a partygoer from going to a private location with another, reminding someone that intoxication makes consent impossible, etc., both women and men may not know what to say or do to intervene. Finally, the failure to intervene due to audience inhibition barrier may be greater for men than women to the extent that gender norms inhibit men from preventing other men from crossing the sexual consent line. For example, anecdotal and news reports suggest that some male groups may have norms against interfering with another's sexual conquest or have norms supporting maximizing sexual conquests irrespective of consent. Several studies have found that perceived norms affect men's sexual assault bystander intervention (Carlson 2008; Fabiano et al. 2003). Furthermore, women's greater empathy with the potential victim may result in reduced susceptibility to the audience inhibition barrier; this empathic affect may override evaluation apprehension for women more than men.

\section{The Current Study}

The correlational study described below provides a preliminary test of a situational model of sexual assault bystander intervention based on Latane and Darley's (1970) five barrier situational model of bystander intervention. It was intended to determine whether the model might be useful for the study of sexual assault prevention bystander intervention, to determine whether some barriers to intervention may be larger than others, and to examine the ways in which gender may influence application of the model to prevention programming. Men and women responded to items measuring the five hypothesized barriers to sexual assault bystander intervention: failure to notice, failure to identify the situation as high risk, failure to take responsi bility for intervening, failure to intervene due to a skills deficit, and failure to intervene due to audience inhibition. Items measuring a potential victim's "worthiness" (e.g., sexual provocativeness or intoxication) and the bystander's relationship to the potential perpetrator and victim were also studied for their influence on sexual assault bystander intervention. Participants also responded to items regarding their sexual assault bystander intervention behavior in regards to friends and non-friends. Participant gender was studied as an independent variable affecting bystander intervention and as a potential moderator of the effects of the various factors on bystander intervention.

Hypotheses

H1: It is expected that the five barrier situational model of bystander intervention is applicable to sexual assault bystander intervention. The five bystander intervention barriers identified by the situational model were expected to be negatively correlated with sexual assault bystander intervention for both women and men, and in a regression analysis the barriers were expected to account for a significant portion of the variance in bystander intervention.

H2: It was expected that men's scores on all of the bystander intervention barriers, except the failure to intervene due to a skills deficit barrier, would be significantly higher than women's. Exploratory analyses regarding the relative influence of the barriers on bystander intervention behavior were also conducted although no specific predictions were made.

H3: It was predicted that knowing the potential victim or perpetrator would influence bystander intervention behavior. More specifically, women were expected to agree that they would be more likely to intervene when the potential victim is a friend than when the potential victim is a non-friend; men were expected to agree they would be more likely to intervene when the potential perpetrator is a friend rather than a non-friend.

H4: Both women and men were expected to agree that when the potential victim made choices that increased her sexual assault risk they would be less inclined to intervene on her behalf; this "worthiness" effect was expected to be greater for men than women.

\section{Method}

Participants

Participants were 378 female and 210 male undergraduate students from sixty academic majors at a central coast California public university. The mean age was 19.9 , with a standard deviation of 2.08. Close to one-third of participants $(30.8 \%)$ identified themselves as first-year students, $24 \%$ second-year, $20.6 \%$ third-year, $16.3 \%$ fourth-year, and $8 \%$ were in their fifth-year or higher. Ethnicity was primarily White $(73 \%)$, followed respectively by individuals who identified themselves as having multiple ethnicities $(8.4 \%)$, 
Asian Americans (7.8\%), Latin Americans/Hispanics (3.4\%), African Americans (1.9\%), those that described themselves as Other (1.9\%), Pacific Islanders (1.7\%), Middle Eastern/Arab (0.7\%), and Native American (0.7\%). Some $(0.7 \%)$ declined to specify their ethnicity. Approximately $14 \%$ of women and $19 \%$ of men identified themselves as being in a sorority or fraternity and $5 \%$ of women and $16 \%$ of men were student athletes. Most data ( $85 \%$ ) was collected in general education courses, $8 \%$ from students in psychology courses, and 7\% from a student convenience sample (students in the university union, cafeteria, and library).

\section{Measure}

Items were created by the author and an undergraduate research team and based on the situational model. Pretesting led to the elimination of items deemed redundant by pretest respondents and to minor item rewording. Participants responded to all items with a 7 -point Likert scale ( $1=$ Strongly Disagree, 2=Disagree, 3=Somewhat Disagree, 4=Neither Agree nor Disagree, 5=Somewhat Agree, 6=Agree, 7= Strongly Agree) and "don't know" (0) and "non-applicable" (8) options were also provided. It should be noted that the study measures were part of a data collection that included multiple measures on several different topics related to sexual assault prevention. Consequently, questionnaire "space" limited the number of items. Also, due to data collection constraints, participants were not measured multiple times so no test-retest reliability data is available. Because this is a new area of study, other measures for purposes of establishing validity were unavailable at the time data were collected.

\section{Barriers to Sexual Assault Bystander Intervention}

Sixteen items were used to measure the bystander intervention barriers (Appendix 1). The first barrier, failure to notice (one item) measured distractedness. The second barrier, failure to identify situation as high risk (a mean of three items, $\alpha=.72$ ), measured ambiguity and pluralistic ignorance. The third barrier, failure to take responsibility for intervening was a mean of eight items, $\alpha=.85$ and included items measuring diffusion of responsibility (two items), worthiness of the victim (four items), and relationship of the bystander to the potential victim or potential perpetrator (two items). The fourth barrier, failure to intervene due to a skills deficit was with a mean of two items reflecting uncertainty about how to intervene $(\alpha=.89)$. Finally, the fifth barrier, failure to intervene due to audience inhibition was a mean of two items, one about hesitation to intervene due to a concern of appearing foolish and another about intervention likelihood being reduced by not having the support of others $(\alpha=.70)$.

\section{Bystander Intervention Behavior}

Separate bystander intervention behavior items were created for women and men because the desired behaviors are somewhat different for each gender (Appendix 2). Women responded to four statements regarding their sexual assault bystander intervention in regards to friends (mean subscale $\alpha=.77$ ) and four statements regarding their sexual assault bystander intervention in regards to women in general (mean subscale $\alpha=.85$ ). A mean of the eight items from both women's subscales was used to create an overall bystander intervention index and yielded a Cronbach's alpha of .85. Similarly, men responded to four statements regarding their sexual assault bystander intervention in regards to friends (mean subscale $\alpha=.73$ ) and four statements regarding their sexual assault bystander intervention in regards to men they don't know (mean subscale $\alpha=.76$ ). The eight items from both men's subscales were also combined into a mean index of bystander intervention $(\alpha=.83)$.

Additionally, both men and women indicated extent of agreement with two statements, one about whether participants would be more likely to intervene if they knew the potential victim and one about whether they would be more likely to intervene if they knew the potential perpetrator (Appendix 2).

\section{Procedure}

Undergraduate women research assistants, either individually or in pairs, went to discussion sections of a large introductory psychology class and to general education classes. They also went to the student union, popular campus eating spots, and library and collected data. The research assistants introduced themselves as psychology majors helping a psychology professor conduct research on sexual assault prevention attitudes, opinions, and behaviors. They told potential participants that results would be used to improve sexual assault prevention programs on campus and that participation was expected to take approximately 15 min. Participants were provided with an informed consent which included information about local sexual assault resources, the questionnaire, and a plain white envelope. Participants were instructed to read the informed consent prior to beginning the questionnaire, and upon completion, to detach the consent form for their records, and seal their anonymous questionnaire in the envelope. Envelopes were then collected or, in some cases, brought to the front of the room and placed in a larger envelope. All participants were treated according to APA ethical guidelines. 


\section{Results}

Cases were excluded from analyses using variables for which data was missing or either the "don't know" or "nonapplicable" option was chosen. Consequently, the number of cases varied depending on the analysis.

\section{Descriptive Data Analyses}

The means and standard deviations of the main study measures appear in Table 2. A MANOVA (measure by gender) was significant, Wilks' Lambda $=.241, F=5.13$ (6, $455), p<.001, \eta^{2}=.064$. Following the MANOVA, univariate ANOVAs (Table 2) were conducted and yielded significant gender differences for all measures with the exception of the Failure to Intervene Due to a Skills Deficit barrier and the item "I am more likely to intervene if I know the victim."

\section{Primary Analyses}

Findings support $H I$, the hypothesis that the five barrier situational model of bystander intervention is applicable to sexual assault bystander intervention. $H 1$ predicted that the five bystander intervention barriers of the situational model would be negatively correlated with bystander intervention behavior for both women and men and in a regression analysis that the barriers would account for a significant portion of the variance in bystander intervention. In support of $H 1$, all coefficients (see Table 3 ) were significant with alpha at .01 or greater with two exceptions of .05 .

A hierarchical regression procedure was conducted separately for men and women with bystander intervention (the 8item indexes combining "friend" and "stranger" intervention) as the dependent variable and the five barrier measures entered in one block as predictor variables (see Table 4 for unstandardized and standardized beta coefficients). In sup- port of $H 1$, for women, $R^{2}$ was $.19, F(5,244)=11.61$, $p<.001$. For men, $R^{2}$ was $.26, F(5,135)=9.23, p<.001$. With all variables entered, the failure to take responsibility barrier predicted a unique portion of the variance in bystander intervention behavior over and beyond the other variables for both men and women. For women, the failure to intervene due to a skills deficit also predicted a unique portion of the variance.

H2 predicted that men's scores on the bystander intervention barriers would be significantly higher than women's scores, with the exception of the failure to intervene due to a skills deficit. A 2 (gender) $\times 5$ (barrier) mixed-model ANOVA supported H2. The gender x barrier interaction was not significant, $F(1,455)=2.43$, ns. As expected, women and men differed on the barrier factor, $F$ $(1,455)=15.49, p<.001$. A pairwise comparison (LSD, $p<.01$; mean difference .37) confirmed that the barriers were greater for men $(M=4.22, \mathrm{SD}=.97)$, than for women $(M=3.84, \mathrm{SD}=.06)$. A posteriori $t$-tests (alpha .01 to control for Type I error) found that men had higher means on all barriers with the exception of the failure to intervene due to a skills deficit barrier ( $n s)$.

Although no predictions were made regarding the relative influence of the barriers, it is notable that a main effect for barrier was found, $F(1,455)=57.78, p<.001$. As shown in Table 2, pairwise comparisons (LSD, $p<.01$ ) found significant differences between barrier subscales. Generally speaking, the failure to notice barrier and failure to intervene due to a skills deficit barrier were the largest and the failure to take intervention responsibility and failure to intervene due to audience inhibition barriers were the smallest.

H3 predicted that knowing the potential victim or perpetrator would influence bystander intervention behavior and was supported by the data. Women were expected to agree that they would be more likely to intervene when the potential victim is a friend than when the potential victim is a non-friend; men were expected to agree they would be

Table 2 Measure means and (SDs) by gender.

\begin{tabular}{llll}
\hline Measure & Women & Men & $F(1,566)$ \\
\hline Failure to notice $^{(2,3,5)}$ & $4.13(1.45)$ & $4.51(1.5)$ & $8.28^{*}$ \\
Failure to identify risk $^{(1,3,5)}$ & $3.96(1.19)$ & $4.29(1.12)$ & $9.10^{*}$ \\
Failure to take responsibility $^{(1,2,4,5)}$ & $3.70(1.04)$ & $4.29(.98)$ & $37.75^{* *}$ \\
Failure to intervene due to skills deficit $^{(3,5)}$ & $4.16(1.64)$ & $4.24(1.52)$ & Ns \\
Failure to intervene inhibition $^{(1,2,3,4)}$ & $3.20(1.36)$ & $3.80(1.34)$ & No \\
Know potential victim & $5.72(1.5)$ & $5.86(1.45)$ & $5.66(1.41)$ \\
Know potential perpetrator & $5.14(1.7)$ & $13.92^{* *}$ \\
\hline
\end{tabular}

A seven point Likert scale was used for all items and measures ( 1 strongly disagree, 2 disagree, 3 somewhat disagree, 4 neither agree nor disagree, 5 somewhat agree, 6 agree, 7 strongly agree). Superscripts indicate significant subscale differences for the sample as a whole $(p<.01) . N=378$ women and 210 men

$* p<.01 ; * * p<.001$ 
Table 3 Barrier subscale correlations with bystander intervention (BI).

\begin{tabular}{|c|c|c|c|c|c|c|c|c|}
\hline Variables & 1 & 2 & 3 & 4 & 5 & 6 & 7 & 8 \\
\hline Failure to notice & & $.57 * * *$ & $.35 * * *$ & $.29 * * *$ & $.33 * * *$ & $.25 * *$ & $.24 * * *$ & $.20 * *$ \\
\hline Failure to identify situation as risky & $.56 * * *$ & & $.44 * * *$ & $.50 * * *$ & $.47 * * *$ & $.31 * * *$ & $.22 * *$ & $.34 * * *$ \\
\hline Failure to take responsibility & $.38 * * *$ & $.51 * * *$ & & $.51 * * *$ & $.56 * * *$ & $.38 * * *$ & $.22 * *$ & $.40 * * *$ \\
\hline Failure to intervene due to skills deficit & $.20 * *$ & $.39 * * *$ & $.47 * * *$ & & $.66 * * *$ & $.35 * * *$ & $.15^{*}$ & $.40 * * *$ \\
\hline Failure to intervene due to audience inhibition & $.23 * *$ & $.47 * * *$ & $.59 * * *$ & $.70 * * *$ & & $.27 * * *$ & $.13^{*}$ & $.32 * * *$ \\
\hline BI total & $.24 * *$ & $.39 * * *$ & $.43 * * *$ & $.37 * * *$ & $.41 * * *$ & & $.85 * * *$ & $.89 * * *$ \\
\hline BI friend & $.32 * * *$ & $.36 * * *$ & $.40 * * *$ & $.29 * * *$ & $.31 * * *$ & $.86 * * *$ & $.54 * * *$ & \\
\hline BI stranger & $.15^{*}$ & $.29 * * *$ & $.25 * * *$ & $.34 * * *$ & $.34 * * *$ & $.91 * * *$ & $.60 * * *$ & \\
\hline
\end{tabular}

Coefficients above the diagonal are for women $(n=250)$, below the diagonal for men $(n=141)$

$* p<.05 ; * * p<.01 ; * * * p<.001$

more likely to intervene when the potential perpetrator is a friend rather than a non-friend. Paired samples t-tests were conducted to compare scores on the bystander intervention friends subscale and the bystander intervention strangers subscale. These were conducted separately for women and men (recall that the subscales were comprised of different items for each gender). In both cases, bystander intervention was significantly greater in the case of friends (see Table 5). Mean responses to two items asking directly about the influence of knowing the potential victim ("I am more likely to intervene to prevent sexual assault if I know the potential victim than if I do not," and "I am more likely to intervene to prevent sexual assault if I know the potential perpetrator than if I do not") also support $H 3$ (see Table 2) as means on the items reflected agreement.

$\mathrm{H} 4$ predicted that both women and men would agree that when the potential victim made choices that increased her sexual assault risk they would be less inclined to intervene on her behalf; this "worthiness" effect was expected to be greater for men than women. Consistent with $H 4$, a 2 (gender) $\times 4$ (worthiness items) mixed-model ANOVA found a main effect for gender, $F(1,536)=44.72, p<.001$, and a pairwise comparison (LSD, $p<.001$; mean difference .76) confirmed that men $(M=3.86, \mathrm{SD}=1.26)$, more strongly agreed than women $(M=3.10, \mathrm{SD}=1.26)$ that worthiness affected their intervention likelihood. Gender differences were found on all four worthiness items. A main effect for worthiness was also found, $F(1,536)=232.17, p<.001$. Table 6 shows results from pairwise comparisons (LSD, $p<.001)$ signifying that the potential victim's intoxication had the smallest impact on intervention intentions. The gender $\times$ worthiness interaction was significant, $F(1,536)=$ 13.76, $p<.001$, indicating that the differences between genders varied based on worthiness item. Specifically, the difference between the genders was smaller on the victim intoxication item (mean difference $=.45$ ) than it was on the other three items (where mean differences were .91, .82, and .83).

\section{Discussion}

Bystander intervention is a potentially potent tool in the primary prevention of sexual assault but more research is needed to guide prevention programming (Banyard 2008). If people can learn to recognize situations in which others are at risk for sexual assault, take responsibility for intervening, know how to intervene, and follow through with action, then sexual assault could potentially be reduced. The five barrier situational model of bystander intervention suggests that distraction, ignorance and ambiguity, failure to take responsibility, skills deficits, and audience inhibition may be barriers to bystander intervention (Latane and Darley 1970). Findings from this explor-

Table 4 Summary of hierarchical regression analysis for barrier variables predicting bystander intervention.

\begin{tabular}{|c|c|c|c|c|c|c|}
\hline \multirow[t]{2}{*}{ Variable } & \multicolumn{3}{|c|}{ Women } & \multicolumn{3}{|l|}{ Men } \\
\hline & $B$ & SE $B$ & $B$ & $B$ & SE $B$ & $\mathrm{~B}$ \\
\hline \multicolumn{7}{|l|}{ Step 1} \\
\hline Failure to notice & .05 & .05 & .07 & .00 & .06 & .01 \\
\hline Failure to identify situation as risky & .07 & .07 & .09 & .17 & .10 & .17 \\
\hline Failure to take intervention responsibility & .25 & .07 & $.25 * *$ & .24 & .11 & $.21 *$ \\
\hline Failure to intervene due to skills deficit & .11 & .05 & $.19 *$ & .08 & .08 & .12 \\
\hline Failure to intervene due to audience inhibition & .04 & .06 & .06 & .10 & .10 & .12 \\
\hline
\end{tabular}

$* p<.05 ; * * p<.01$ 
Table 5 Paired samples $t$ tests for bystander intervention friends (BI F) and strangers (BI S).

\begin{tabular}{|c|c|c|c|c|c|c|}
\hline & \multicolumn{2}{|l|}{ BI F } & \multicolumn{2}{|l|}{ BI S } & \multirow[t]{2}{*}{ CI } & \multirow[t]{2}{*}{$t^{*}$} \\
\hline & $M$ & SD & $M$ & SD & & \\
\hline Women & 5.52 & 1.02 & 4.90 & 1.20 & .49 .74 & 9.63 \\
\hline Men & 5.03 & 1.06 & 4.55 & 1.44 & $.30 \quad .64$ & 5.30 \\
\hline
\end{tabular}

Degrees of freedom for women was 286 and for men 171

*All significant at $p<.001$

atory study support the applicability of the situational model of bystander intervention to bystander intervention in situations high in risk for sexual assault. For both men and women, all five barriers were negatively correlated with sexual assault bystander intervention behavior and together accounted for a significant portion of the variance in bystander intervention behavior. The study also found that the bystander intervention barriers identified by the situational model pose a greater barrier to men's intervention than women's intervention, with the exception of the failure to intervene due to a skills deficit. These gender differences could result from women's awareness of their greater sexual assault risk relative to men's, and their identification with, and subsequent empathy for sexual assault survivors (Gerber et al. 2004; Jimenez and Abreu 2003, Lambdin 2005).

The situational model suggests that a failure to notice a high-risk situation is the first barrier to bystander intervention. This barrier may be of special concern in group situations where people are focused on their own partying or social interactions. Results from this study suggest this is one of the largest barriers to bystander intervention. Reducing this barrier could include informing people about the barrier and training them to be alert for it, and promoting the idea that party hosts or designated drivers should assume this as part of their role. Study results also indicate that a failure to identify a situation as high-risk is a significant intervention barrier, therefore, it may be useful for sexual assault bystander intervention education to include components designed to help participants identify real-world situations high in sexual assault risk. Such situations may include intoxication, going to a private location with an acquaintance, "red flag" perpetrator behaviors, and situations where sexual consent is not possible due to factors such as intoxication or age. In a successful college bystander education program, Banyard et al. (2007) included program content to improve students' ability to identify high-risk situations. Survey research can be used to identify informational deficits so that they can be targeted for remediation. Intervention education directed at reducing this barrier might also include information on the dangers of pluralistic ignorance so that bystanders are less likely to interpret others' inaction as meaning no sexual assault threat is present.

Increasing the salience of prosocial bystander intervention norms may be helpful in overcoming the barriers of failure to take intervention responsibility and failure to intervene due to audience inhibition. For example, the Mentors in Violence Project (Katz 1995) encourages male student-athletes to become leaders in delegitimizing "rapesupportive" and "battering-supportive" attitudes. Injunctive normative information ("what people should do" norms) emphasizing that peers believe bystander intervention is appropriate can be used in presentations and marketing. This is consistent with a social norms marketing approach to sexual assault prevention (see Berkowitz 2004). Such information should be derived from local surveys. For example, "Over $90 \%$ of ABC university students say it's your responsibility to intervene when another is at-risk for sexual assault," or " $97 \%$ of ABC university men say you should interfere with another guy's 'action' if it might prevent a sexual assault."

Because study results also suggest that some bystanders may fail to intervene due to a skills deficit, bystander

Table 6 Victim worthiness: means and (SDs) by gender.

\begin{tabular}{|c|c|c|}
\hline Worthiness variables & Men & Women \\
\hline Less likely to intervene if potential victim made choices that increased risk ${ }^{(2,3,4)}$ & $4.08(1.57)$ & $3.16(1.48)$ \\
\hline Less likely to intervene if potential victim dressed provocatively, or acted provocatively ${ }^{(1,4)}$ & $4.28(1.63)$ & $3.47(1.65)$ \\
\hline Feel less responsible for intervening if potential victim is dressed provocatively, or acted provocatively ${ }^{(1,4)}$ & $4.27(1.58)$ & $3.44(1.62)$ \\
\hline Less likely to intervene if potential victim is intoxicated ${ }^{(1,2,3)}$ & $2.86(1.28)$ & $2.41(1.30)$ \\
\hline
\end{tabular}

Complete items are in Appendix 1. Women and men's means were all significantly different at $p<.001$. Superscripts indicate significant differences between variables for the entire sample $(p<.01)$. Seven point Likert scale $(1$ strongly disagree, 2 disagree, 3 somewhat disagree, 4 neither agree nor disagree, 5 somewhat agree, 6 agree, 7 strongly agree ( $N=345$ women and 193 men) 
intervention education may be more effective when it includes specific information regarding action options and the language of intervention. For instance, university students should be provided with intervention options such as getting the potential victim out of the situation, joining with others to ask a potential perpetrator to back off, reminding a potential perpetrator that consent is not possible due to the potential victim's age or intoxication, or calling an authority. Potential bystander interveners may also need simple phrases for prevention intervention such as, "You're coming with us. We can't leave you here and put you at risk for sexual assault" or, "Sorry, she's too intoxicated to provide consent." Banyard et al. (2007) used active learning exercises, including role plays, to help potential bystanders develop the skills needed for sexual assault intervention. Potter et al. (2008) used posters with scenarios and specific behavioral suggestions to promote knowledge of bystander intervention behaviors in regards to several types of violence against women.

As predicted based on past research (Gerber et al. 2004; Grant et al. 1995), the perception that a potential victim made choices or behaved in ways that increased her sexual assault risk was found to reduce bystander intervention intentions, with this effect greater for men than women. This finding underscores the need for sexual assault prevention interventions, regardless of focus, to also emphasize that regardless of what a woman did or did not do, it is not her fault if she is sexually assaulted. For example, we can add to presentations phrasing such as "Although there are things women can do to reduce their sexual assault risk, this does not mean that if a woman is sexually assaulted it's her fault - the blame always lies with the person that committed the assault." To reinforce the belief that it's never the survivor's fault, we can also use normative information (i.e., " $95 \%$ of $\mathrm{ABC}$ university men agree, it doesn't matter how a woman is dressed, how she's acting, or whether she's intoxicated, you should intervene if she's at risk for sexual assault."). Emphasizing that it's never the survivor's fault may also increase empathy and support for survivors. Research on how we may effectively reduce this "worthiness effect" is needed to guide these efforts.

Some research (Gottleib and Carver 1980; Howard and Crano 1974; Levine et al. 2002) suggests the relationship of the bystander to the potential victim or perpetrator increases people's feelings of intervention responsibility but Banyard (2008) found no relationship between knowing the victim and sexual assault bystander intervention behavior. This study found that both men and women agreed that knowing the potential victim or perpetrator positively affected their bystander intervention likelihood. Additionally, for women sexual assault bystander intervention was greater when the potential victim was a friend, and men's intervention in regards to potential perpetrators was greater when that person was a friend. Although more research is needed, efforts to promote bystander intervention might capitalize on these findings. Normative data can be used to emphasize peoples' responsibility to reduce their friends' risk of sexual assault and friends' risk of sexually assaulting. For example, " $98 \%$ of ABC university women say you should never leave your woman friend alone at a bar or party;" or " $97 \%$ of ABC university men agree that to keep your friends out of trouble, you should stop them from doing things that might meet the definition of sexual assault." It is possible that prevention bystander intervention efforts may be more successful when promoted as consistent with friendship norms, or as consistent with important collectivist social identities (i.e., "sisterhood" or "brotherhood" norms in the case of sororities and fraternities, or team norms in the case of athletes).

This study found that men agreed significantly more than women that knowing the potential perpetrator made them more likely to intervene. This finding supports a "black sheep effect" that may promote intervention rather than an ingroup bias that might inhibit it (Levine et al. 2002). It is possible that men's bystander intervention could be enhanced by taking advantage of this effect. This could be done by emphasizing how sexual assault perpetrators harm the reputation of all men (e.g., "Don't let a few bad men hurt the reputation of all men. Intervene when another man is at risk for sexually assaulting") or, how the group (team or fraternity) is hurt when members are accused of sexual assault perpetration.

\section{Limitations}

Like most studies utilizing self-report, this study is subject to social desirability biases. Despite efforts to ensure anonymity, participants may have been reluctant to acknowledge that their intervention actions might be influenced by victim worthiness or social acceptability (means on these items were especially low). Bystander intervention behavior means were high and while this may have resulted from the fact that many study participants were likely exposed to university sexual assault prevention programming and social marketing that included bystander intervention education, it could also result from social desirability biases.

Conceptual replications of the study are desired due to the abbreviated measures of bystander intervention and barriers. Ideally, such replications would include measures of actual bystander behavior. This study was part of a larger study on sexual assault risk reduction and prevention norms and the number of items was consequently limited. Although the measures had acceptable internal reliabilities and face validity, psychometrically sound measures are needed for further study. Another shortcoming is limited realism 
stemming from general items about the intervention barriers. Participants may have had difficulty anticipating how they would respond to the barriers and their real-world responses could differ from their estimations. Replications of the study might employ the use of vignettes to increase realism.

Lack of diversity in the sample is another shortcoming. Participants were young adults at a public California university and primarily White. All but seven identified themselves as heterosexual. Additionally, although some barriers may operate in some subcultures (i.e., fraternities, sororities, first-year students, etc.) more than others, this hypothesis was not tested due to small subgroup sample sizes. This paper focused on a situational model of bystander of intervention in regards to acquaintance sexual assault in an American university social context and generalization to other contexts and types of sexual assault cannot be assumed; the barriers may operate to a greater or lesser extent depending on the social context. Finally, although responses were anonymous, there is the possibility that results were biased because the data was collected by women research assistants.

\section{Conclusions}

As Latane and Darley (1970) noted, the decision to intervene is complex and bystanders must surmount a number of barriers before helping. This exploratory study supports the idea that all five barriers postulated by a situational model of prevention bystander intervention may influence intervention likelihood. The cumulative impact of the barriers on sexual assault prevention bystander intervention may be considerable given that bystanders must successively surmount all five barriers before intervening. Programs intended to promote bystander intervention in situations at-risk for sexual assault may be more effective if they address the barriers identified by a situational model of sexual assault prevention bystander intervention. Many of these barriers may be addressed through the presentation of common high-risk scenarios and intervention options during the mandatory sexual assault prevention and risk reduction programming common at universities. Prevention programming should also emphasize bystander responsibility and persuade potential bystanders that intervention is appropriate regardless of choices the potential victim made. Social marketing can be used to reinforce key messages. For example, reminder messaging can appear in student newspaper or radio ads, on bookmarks given away at the library or with textbook purchases, and on prompts in public locations such as on the back of residence hall bathroom stalls. These tactics may be useful in promoting prevention bystander intervention norms and intervention behaviors and should be examined by future researchers for their effectiveness as sexual assault prevention tools.
Acknowledgment The author would like to thank the editor and anonymous reviewers for their comments as well as undergraduates Alyssa Bogetz, Kelli June, Jennifer Ledbetter, Caitlin Busso, Stephanie Marasco, Caitlin Madden, Linda Sosa, and Casey Tolosa, who assisted in various tasks such as collecting literature, question naire pretesting, data collection, data entry, and proofreading.

\section{Appendix 1}

Barrier Subscale Items

Failure to Notice

1. At a party or bar, I am probably too busy to be aware of whether someone is at risk for sexual assault.

Failure to Identify Situation as High Risk

1. In a party or bar situation, I find it hard to tell whether a guy is at risk for sexually assaulting someone.

2. In a party or bar situation, I think I might be uncertain as to whether someone is at-risk for being sexually assaulted.

3. Even if I thought a situation might be high in sexual assault risk, I probably wouldn't say or do anything if other people appeared unconcerned.

Failure to Take Intervention Responsibility

1. Even if I thought someone was at risk for being sexually assaulted, I would probably leave it up to others to intervene. (diffusion of responsibility)

2. If I saw someone I didn't know was at risk for being sexually assaulted, I would leave it up to his/her friends to intervene. (diffusion of responsibility)

3. I am less likely to intervene to reduce a person's risk of sexual assault if I think she/he made choices that increased their risk. (worthiness)

4. If a person is dressed provocatively, or acts provocatively, I am less likely to intervene to prevent others from taking sexual advantage of them. (worthiness)

5. If a person is extremely intoxicated I am less likely to intervene to prevent others from taking sexual advantage of them. (worthiness)

6. If a person is dressed provocatively, or acts provocatively, I feel less responsible for preventing others from taking sexual advantage of them. (worthiness)

7. I am more likely to intervene to prevent sexual assault if I know the potential victim than if I do not. (relationship of bystander to potential victim)

8. I am more likely to intervene to prevent sexual assault if I know the person that may be at risk for committing sexual assault than if I do not know him. (relationship of bystander to potential perpetrator) 
Failure to Intervene Due to a Skills Deficit

1. Although I would like to intervene when a guy's sexual conduct is questionable, I am not sure I would know what to say or do.

2. Even if I thought it was my responsibility to intervene to prevent sexual assault, I am not sure I would know how to intervene.

Failure to Intervene Due to Audience Inhibition

1. I am hesitant to intervene when a man's sexual conduct is questionable because I am not sure other people would support me.

2. Even if I thought it was my responsibility to intervene to prevent a sexual assault, I might not out of a concern I would look foolish.

\section{Appendix 2}

Bystander Intervention Items

\section{Women}

1. To reduce sexual assault risk, I never leave a friend alone at a party or bar even if the friend insists she'll be all right.

2. I try to be a good friend by not letting my intoxicated female friends go to a private location with a guy.

3. To reduce sexual assault risk, I discourage my friends from going to a private location with a male acquaintance.

4. I remind my female friends to take actions to reduce sexual assault risk.

5. If I see a man pressuring a woman to leave a party or bar with him, I intervene.

6. If I see a situation in which it looks like someone will end up being taken advantage of sexually, I intervene.

7. If I see someone "putting the moves" on a person that is very intoxicated, I say or do something about it.

8. If I hear someone making inappropriate sexual comments to someone else, I say or do something about it.

Men

1. To keep my friends out of trouble, I stop them from doing things that might meet the definition of sexual assault.

2. I intervene if I see a friend trying to take advantage of someone's intoxicated state to have sex with them.

3. I say something if I hear a friend talking about getting someone intoxicated in order to have sex with them.

4. I discourage my friends from talking about women in sexually degrading ways.
5. I will interfere with another guy's "action" if I think it might stop them from possibly committing a sexual assault.

6. I intervene if I see a stranger or acquaintance trying to take advantage of someone's intoxicated state to have sex with them.

7. I say something if I hear a stranger or acquaintance talking about taking sexual advantage of someone's intoxicated state.

8. I discourage strangers or acquaintances if I hear them talking about women in sexually degrading ways.

Both Women and Men

1. I am more likely to intervene to prevent sexual assault if I know the potential victim than if I do not.

2. I am more likely to intervene to prevent sexual assault if I know the potential perpetrator than if I do not.

\section{References}

Abbey, A., Ross, L. T., McDuffie, D., \& McAuslan, P. (1996). Alcohol and dating risk factors for sexual assault among college women. Psychology of Women Quarterly, 20, 147169.

Anderson, L. A., \& Whiston, S. C. (2005). Sexual assault education programs: a meta analytic examination of their effectiveness. Psychology of Women Quarterly, 29, 374388.

Aosved, A. C., \& Long, P. J. (2006). Co occurrence of rape myth acceptance, sexism, racism, homophobia, ageism, classism, and religious intolerance. Sex Roles, 55, 481492.

Bachar, K. J., \& Koss, M. P. (2001). From prevalence to prevention: Closing the gap between what we know about rape and what we do. In C. M. Renzetti, R. K. Bergen, \& J. L. Edelson (Eds.), Sourcebook on violence against women (pp. 117 142). Thousand Oaks: Sage.

Banyard, V. (2008). Measurement and correlates of prosocial bystander behavior: the case of interpersonal violence. Violence and Victims, 23, 8397.

Banyard, V. L., Plante, E. G., \& Moynihan, M. M. (2004). Bystander education: bringing a broader community perspective to sexual violence prevention. Journal of Community Psychology, 32, 6179.

Banyard, V. L., Moynihan, M. M., \& Plante, E. G. (2007). Sexual violence prevention through bystander education: an experi mental evaluation. Journal of Community Psychology, 35, 463 481.

Batson, D. C., Eklund, J. K., Chermok, V. L., Hoyt, J. L., \& Ortiz, B. G. (2007). An additional antecedent of empathic concern: valuing the welfare of the person in need. Journal of Personality and Social Psychology, 93, 6574.

Berkowitz, A. D. (2002). Fostering men's responsibility for preventing sexual assault. In P. A. Schewe (Ed.), Preventing violence in relationships: Intervention across the lifespan (pp. 163 196). Washington, DC: American Psychological Association.

Berkowitz, A. D. (2004). An overview of the social norms approach. In L. Lederman, L. Stewart, F. Goodhart, \& L. Laitman (Eds.), Changing the culture of college drinking: A socially situated prevention campaign (pp. 187 208). Creskill, NJ: Hampton Press. 
Brecklin, L. R., \& Ullman, S. E. (2005). Self defense or assertiveness training and women's responses to sexual attacks. Journal of Interpersonal Violence, 20, 738762.

Breitenbecher, K. H. (2000). Sexual assault on college campuses: is an ounce of prevention enough? Applied and Preventative Psychol ogy, 9, 2352.

Burt, M. R. (1980). Cultural myths and supports of rape. Journal of Personality and Social Psychology, 38, 217230.

Carlson, M. (2008). I'd rather go along and be considered a man: masculinity and bystander intervention. Journal of Men's Studies, 16,317

Carr, J. L., \& VanDeusen, K. M. (2004). Risk factors for male sexual aggression on college campuses. Journal of Family Violence, 19, 279289.

Cassidy, L., \& Hurrell, R. (1995). The influence of victim's attire on adolescents' judgments of date rape. Adolescence, 30, 319 323.

Castello, J., Coomer, C., Stillwell, J., \& Cate, K. L. (2006). The attribution of responsibility in acquaintance rape involving ecstasy. North American Journal of Psychology, 8, 411420.

Ching, C. L., \& Burke, S. (1999). An assessment of college students' attitudes and empathy toward rape. College Student Journal, 3, 573583.

Cialdini, R. B., Brown, S. L., Lewis, B. P., Luce, C., \& Neuberg, S. L. (1997). Reinterpreting the empathy altruism relationship: when one into one equals oneness. Journal of Personality and Social Psychology, 73, 481494.

Cramer, R. E., McMaster, M. R., Bartell, P. A., \& Dragna, M. (1988). Subject competence and the minimization of the bystander effect. Journal of Applied Social Psychology, 18, 11331148 .

Deitz, S. R., Tiemann Blackwell, K., Daley, P. C., \& Bentley, B. J. (1982). Measurement of empathy toward rape victims and rapists. Journal of Personality and Social Psychology, 43, 372384.

Eagly, A. H. (1987). Sex differences in social behavior: A social role interpretation. Hillsdale, NJ: Erlbaum.

Eagly, A. H., \& Crowley, M. (1986). Gender and helping behavior: a meta analytic review of the social psychological literature. Psychological Bulletin, 100, 283308.

Fabiano, P. M., Perkins, W., Berkowitz, A., Linkenbach, J., \& Stark, C. (2003). Engaging men as social justice allies in ending violence against women: a social norms approach. Journal of American College Health, 52, 105112.

Fisher, B., Cullen, F., \& Turner, M. (2000). The sexual victimization of college women. Washington, D.C.: U.S. Department of Justice, National Institute of Justice and Bureau of Justice Statistics.

Fischer, P., Greitmeyer, T., Pollozek, F., \& Frey, D. (2005). The unresponsive bystander: are bystanders more responsive in dangerous emergencies. European Journal of Social Psychology, 36,267278

Fogle, J. (2000). Acquaintance rape and the attribution of responsi bility: the role of alcohol and individual differences. Undergrad uate Research Journal of Indiana University SouthBend, 3.

Foubert, J. D. (2000). The longitudinal effects of a rape prevention program on fraternity men's attitudes, behavioral intent, and behavior. Journal of American College Health, 48, 158163.

Gerber, G. L., Cronin, J. M., \& Steigman, H. (2004). Attributions of blame in sexual assault to perpetrators and victims of both genders. Journal of Applied Social Psychology, 34, 21492165.

Gottleib, J., \& Carver, C. S. (1980). Anticipation of future interaction and the bystander effect. Journal of Experimental Social Psychology, 16, 253260.

Grant, J. M., Folger, W. A., \& Hornak, J. N. (1995). College students' perception of victim responsibility in an acquaintance rape situation. College Student Journal, 29, 532535.
Hall, J. A. (1984). Nonverbal sex differences: Communication accuracy and expressive style. Baltimore: Johns Hopkins University Press.

Harari, H., Harari, O., \& White, R. V. (2001). The reaction to rape by American male bystanders. Journal of Social Psychology, 125, 653658.

Harrison, L. A., Howerton, P. M., Secarea, A. M., \& Nguyen, C. Q. (2008). Effects of ingroup bias and gender role violations on acquaintance rape attributions. Sex Roles, 59, 713725.

Howard, W., \& Crano, W. D. (1974). Effects of sex, conversation, location, and size of observer group on bystander intervention in a high risk situation. Sociometry, 37, 491507.

Jimenez, J. A., \& Abreu, J. M. (2003). Race and sex effects on attitudinal perceptions of acquaintance rape. Journal of Counsel ing Psychology, 50, 252256.

Katz, J. (1995). Reconstructing masculinity in the locker room: mentors in violence prevention. Harvard Educational Review, 65, 163174.

Lambdin, C. L. (2005). Acquaintance rape empathy: effects of subject gender, victim gender, and the use of physical resistance. Dissertation Abstracts International: Section B: The Sciences and Engineering, 66(3 B), 1784.

Latane, B., \& Darley, J. M. (1968). Group inhibition of bystander intervention. Journal of Personality and Social Psychology, 10, 215221.

Latane, B., \& Darley, J. M. (1970). The unresponsive bystander: Why doesn't he help. New York: Appleton Century Crofts.

Latane, B., \& Nida, S. (1981). Ten years of research on group size and helping. Psychological Bulletin, 89, 308324.

Levine, M., Cassidy, C., Brazier, G., \& Reicher, S. (2002). Self categorization and bystander non intervention. Journal of $A p$ plied Social Psychology, 32, 14521463.

Lisak, D., \& Miller, P. M. (2002). Repeat rape and multiple offending among undetected rapists. Violence and Victims, 17, 7384.

Loewenstein, G., \& Small, D. A. (2007). The scarecrow and the tin man: the vicissitudes of human sympathy and caring. Review of General Psychology, 11, 112126.

Lonsway, K. A., \& Fitzgerald, L. F. (1994). Rape myths: in review. Psychology of Women Quarterly, 18, 133164.

Norris, J., \& Cubbins, L. A. (1992). Effects of victims' and assailants' alcohol consumption on judgments of their behavior and traits. Psychology of Women Quarterly, 16, 179191.

O'Brien, J. (2001). The MVP program: focus on student athletes. In A. J. Ottens, \& K. Hotteling (Eds.), Sexual violence on campus (pp. 141 161). New York: Springer.

Potter, S. J., Stapleton, J. G., \& Moynihan, M. M. (2008). Designing, implementing, and evaluating a media campaign illustrating the bystander role. Journal of Prevention and Intervention in the Community, 36, 3955.

Rozee, P. D., \& Koss, M. P. (2001). Rape: a century of resistance. Psychology of Women Quarterly, 25, 295311.

Rutkowski, G. K., Gruder, C. L., \& Romer, D. (1983). Group cohesiveness, social norms, and bystander intervention. Journal of Personality and Social Psychology, 44, 545552.

Sampson, R. (2003). Acquaintance rape of college students. U.S. Department of Justice: Office of Community Oriented Policing Services.

Schewe, P. A. (2002). Guidelines for developing rape prevention and risk reduction interventions. In P. A. Schewe (Ed.), Preventing violence in relationships: Intervention across the lifespan (pp. 107 133). Washington, DC: American Psychological Association.

Schult, D. G., \& Schneider, L. J. (1991). The role of sexual provoca tiveness, rape history, and observer gender in perceptions of blame in sexual assault. Journal of Interpersonal Violence, 6, 94101.

Schwartz, S. H., \& Gottleib, A. (1980). Bystander anonymity and reaction to emergencies. Journal of Personality and Social Psychology, 39, 418430. 
Shechory, M., \& Idisis, Y. (2006). Rape myths and social distance toward sex offenders and victims among therapists and students. Sex Roles, 54, 651658.

Shotland, R. L., \& Heinhold, W. D. (1985). Bystander response to arterial bleeding: helping skills, the decision making process, and differentiating the helping response. Journal of Personality and Social Psychology, 49, 347356.

Shotland, R. L., \& Straw, M. K. (1976). Bystander response to an assault: when a man attacks a woman. Journal of Personality and Social Psychology, 34, 990999.

Smith, C. A., \& Frieze, I. H. (2003). Examining rape empathy from the perspective of the victim and the assailant. Journal of Applied Social Psychology, 33, 476498.

Sochting, I., Fairbrother, N., \& Koch, W. J. (2004). Sexual assault of women: prevention efforts and risk factors. Violence Against Women, 10, 7393.
Tjaden, P., \& Thoennes, N. (2000). Full report of the prevalence, incidence, and consequences of violence against women: Find ings from the national violence against women survey. Wash ington, DC: National Institute of Justice.

Ullman, S. E. (2003). A critical review of field studies on the link of alcohol and adult sexual assault in women. Aggression and Violent Behavior: A Review Journal, 8, 471486.

Ullman, S. E. (2007). A 10 year update of review and critique of empirical studies of rape avoidance. Criminal Justice and Behavior, 34, 411429.

Whatley, M. A. (2005). The effect of participant sex, victim dress, and traditional attitudes on causal judgments for marital rape and victims. Journal of Family Violence, 20, 191200.

Workman, J. E., \& Freeburn, E. W. (1999). An examination of date rape, victim dress, and perceiver variables within the context of attribution theory. Sex Roles, 41, 261278. 